\title{
Intranasal insulin treatment improves memory and learning in a rat amyloid-beta model of Alzheimer's disease
}

\author{
S Farzampour, A Majdi, S Sadigh-Eteghad \\ Neurosciences Research Center (NSRC), Tabriz University of Medical Sciences, Tabriz, Iran
}

Received: March 29, 2016

Accepted: July 16, 2016

\begin{abstract}
Recently, insulin has been used as a pro-cognitive agent for the potential treatment of Alzheimer's disease (AD), because of its ability to cross the brain-blood barrier (BBB) by a saturable transport system. This study has been designed to evaluate the effects of intranasal insulin regimen, as a bypass system of BBB, on spatial memory in amyloid-beta $(A \beta)$ model of $A D$ in rat. Unilateral infusion of $A \beta_{25-35}(10 \mathrm{nmol} / 2 \mu 1 / \mathrm{rat})$ into the lateral ventricular region of brain was used to produce a rat model of AD. After a 24-h recovery period, rats received insulin or vehicle via intraperitoneal or intranasal route $(0.1,0.2$, and $0.3 \mathrm{IU})$ for 14 days. Memory function in rats was assessed by Morris water maze test, with 5 days of training and consequent probe test protocol. Different doses of intraperitoneal insulin did not have a significant effect on learning and memory in AD rats. However, intranasal insulin at doses of 0.2 and $0.3 \mathrm{IU}$ improved the learning and memory in A $\beta$-received rats. In conclusion, intranasal insulin as a non-invasive strategy improves spatial learning and memory in AD model.
\end{abstract}

Keywords: intranasal, insulin, memory, Alzheimer's disease, learning

\section{Introduction}

Alzheimer's disease (AD) is the most common neurodegenerative disorder that affects aged population (41). According to the 2010 World Alzheimer's Report, more than 36 million people are living with dementia, and it is expected that this number will be tripled by 2050 $(40,48)$. Cognitive decline, a major symptom exhibited by patients with $\mathrm{AD}$, is associated with amyloid-beta $(\mathrm{A} \beta)$ deposition in the brain tissue $(42,43)$.

In general, $\mathrm{AD}$ is a metabolic disease in which brain glucose utilization and energy production are impaired (16). This disease exhibits metabolic abnormalities, such as glucose metabolism impairment, abnormal insulin receptor signaling, insulin resistance, oxidative stress, and structural abnormalities in proteins (18). Moreover, dementia in sporadic AD type is associated with dysfunction of the insulin receptor followed by decreased glucose transport via glucose transporter 4 (GLUT-4) and decreased glucose metabolism in brain cells (45).

Evidence shows that insulin dysregulation could contribute to the expression of late-life neurodegenerative disorders (13). On the other hand, anti-diabetic drugs have showed beneficial effects on glycolysis and other metabolic alterations during AD (18).

\footnotetext{
Corresponding author: Saeed Sadigh-Eteghad, MPhil, PhD

Neurosciences Research Center (NSRC), Tabriz University of Medical Sciences

5166614756 Tabriz, Iran

Phone/Fax: +98 41 33340730; E-mail: Saeed.sadigetegad@gmail.com
} 
Recently, insulin has received much attention for its potential, beneficial, and protective roles in cognitive function (10). Although long-term insulin therapy may lead to severe hypoglycemia (14) and this risk increases with diabetes (23).

Because of the existence of brain-blood barrier (BBB) in cerebral vasculature, systemic delivery of therapeutics from the circulating blood to the central nervous system (CNS) is not effective for more than $98 \%$ of small molecules and nearly $100 \%$ of large molecules (17).

Therapeutics can be directly introduced into the CNS by intracerebroventricular (i.c.v.) or intraparenchymal injections; however, for multiple dose regimens, both the delivery methods are invasive, risky, and expensive techniques requiring surgical expertise (32). Intranasal delivery of insulin, which was first introduced by W. H. Frey (55), is a noninvasive and rapid brain delivery method, which bypasses the BBB and delivers insulin to the CNS through olfactory and trigeminal nerves $(17,37)$. This method has been successfully used in animal studies and clinical trials $(11,20,39)$.

\section{Materials and Methods}

\section{Experimental design}

Wistar rats (weighing 250-270 g), which were purchased from Laboratory Animal Care Center of Tabriz University of Medical Sciences (TUOMS), were housed in a temperature-controlled environment with an alternating 12-h light/dark cycle for at least 7 days prior to treatment and were fed standard laboratory chow (Pars Khoram dam, Iran). The room temperature was maintained at $22 \pm 2{ }^{\circ} \mathrm{C}$. All stressful conditions were avoided. The experimental procedures were carried out in accordance with the Guide for the Care and Use of Laboratory Animals of the National Institutes of Health (NIH; Publication No. 85-23, revised 1985) and in compliance with the animal care and use committee guidelines of TUOMS.

\section{A $\beta$ preparation and aging}

Peptide aggregation was performed as previously described (44); briefly, $\mathrm{A} \beta_{25-35}$ peptides (Sigma-Aldrich, USA) were dissolved in phosphate-buffered saline at a concentration of $2 \mathrm{mg} / \mathrm{ml}$ and incubated for peptide aging or aggregation at $37{ }^{\circ} \mathrm{C}$ for 4 days.

\section{Surgical procedures}

Unilateral infusion of $\mathrm{A} \beta_{25-35}(10 \mathrm{nmol} / 2 \mu \mathrm{l} / \mathrm{rat})$ into the lateral ventricular region of brain was used to produce a rat model of AD. For this purpose, rats were anesthetized with injection of ketamine $(90 \mathrm{mg} / \mathrm{kg}$, i.p.) and xylazine $(12 \mathrm{mg} / \mathrm{kg}$, i.p.). Body temperature was maintained at $36.5 \pm 0.5{ }^{\circ} \mathrm{C}$ using a heating pad that was regulated by a rectal temperature sensor. The rat head was fixed in the stereotactic apparatus, and the skull was exposed by making an incision in the midline scalp. The stereotaxic coordinates were determined according to the rat brain atlas: anterior-posterior $=-0.8 \mathrm{~mm}$, mediallateral $= \pm 1.6 \mathrm{~mm}$, and dorsal-ventral $=-4.2 \mathrm{~mm} \mathrm{(36).} \mathrm{A} \beta(10 \mathrm{nmol} / \mathrm{rat})$ was injected into the ventricle over $3 \mathrm{~min}$ using a $5-\mu 1$ Hamilton microsyringe and infusion pump. To avoid reflux, the rats were kept restrained, maintaining the injection needle in situ for an additional 5 min after the infusion. After surgery, each rat was kept in a separate cage for $24 \mathrm{~h}$. 


\section{Drug treatments}

Drug and/or vehicle were delivered via intraperitoneal or intranasal route. Separate groups of $\mathrm{A} \beta_{25-35}$-injected rats (15 rats/each group) received normal saline (NS) and/or insulin (Exir Pharmaceuticals, Iran) $(0.1,0.2$, and 0.3 IU) for 14 consecutive days following the surgery procedure. Control group did not receive any treatment. Solutions were freshly prepared on the day of experimentation by dissolving drugs in physiological saline $(0.9 \% \mathrm{NaCl})$. All administrations were done in a constant volume of $20 \mu \mathrm{l}$. For intranasal delivery, each rat was restrained and held with its neck parallel to the floor while a volume of $20 \mu \mathrm{l}(10 \mu \mathrm{l} / \mathrm{each}$ nostril) of liquid was administered using pipettor (30).

\section{Morris water maze (MWM) test}

The MWM consisted of a black circular pool (diameter: $130 \mathrm{~cm}$, height: $60 \mathrm{~cm}$ ) filled with clear water maintained at a temperature of $25 \pm 1{ }^{\circ} \mathrm{C}$. A platform (diameter: $10 \mathrm{~cm}$ ) was placed in the center of one quadrant of the pool. During the training, the platform was constantly maintained $1 \mathrm{~cm}$ below the surface of the water. The maze was located in a room with visual cues. The starting points were pseudo-randomized for each trial. Rats were released to the pool facing toward the wall and were allowed to search for the submerged platform for $60 \mathrm{~s}$. If the rats could find the platform within $60 \mathrm{~s}$, they were allowed to stay on the platform for $20 \mathrm{~s}$; if they could not find the platform, they were directed to the platform and allowed to stay there for $20 \mathrm{~s}$. The rats were subjected to four trials with a 10-min interval between each two trials for 5 consecutive days. The training finished when 5-day trials were completed. On the last day of the trial, the platform was removed and the rats were subjected to probe trial in which they searched for platform for $60 \mathrm{~s}$. Also, the visible platform version of the MWM (platform $1 \mathrm{~cm}$ above the water and marked by a beacon) was used to assess the escape motivation or impairment of visual and/or motor performance.

Data of the escape latency (in training days) and the time spent in the target quadrant (in probe trial) were collected by the video tracking equipment and processed by a computer.

\section{Statistical analyses}

Descriptive data were expressed as mean \pm standard error of mean (SEM). Comparison of different groups was carried out by a repeated measure or a one-way ANOVA followed by the post hoc Tukey test. All analyses were performed using IBM SPSS Statistics software (version 22 for Windows; SPSS Inc., Chicago, IL, USA). In all comparisons, $p<0.05$ was considered significant.

\section{Results}

Visible platform phase of $M W M$

There was no significant difference between the treatment groups in the distance traveled and the mean swim speed (data not shown).

\section{Effect of intraperitoneal insulin administration on working memory}

The average escape latency in the hidden platform phase decreased within the training days. Moreover, group effect was a significant determinant of escape latency time. Two-way 


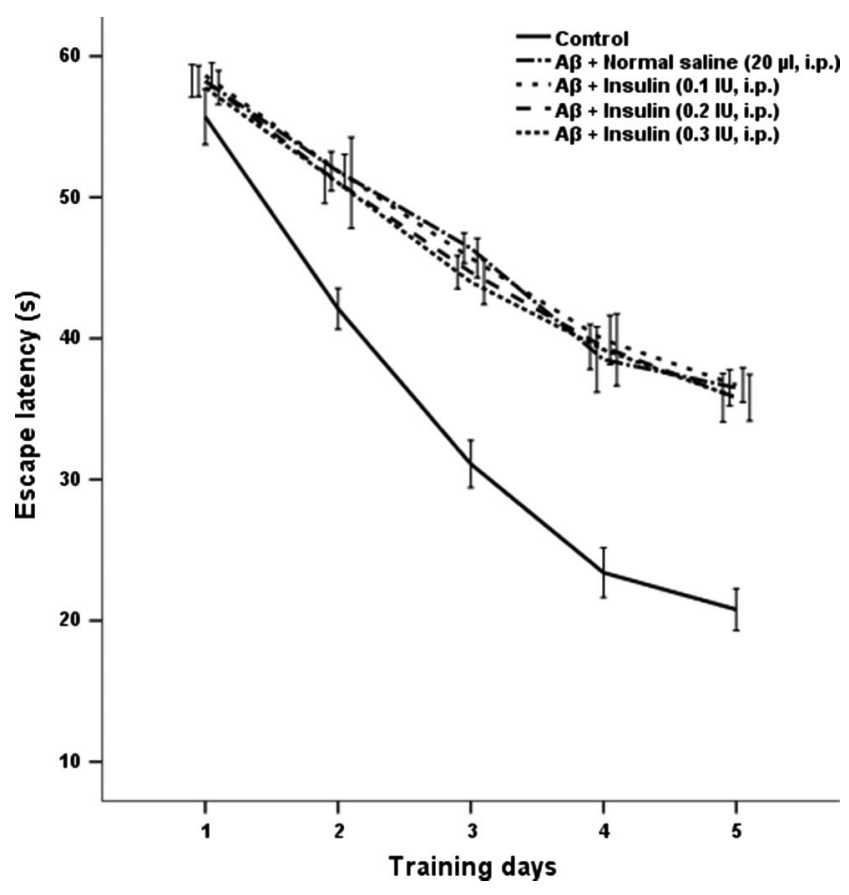

Fig. 1. Average escape latencies during training days on the hidden platform task in different groups. Each dot represents the mean \pm SEM. (i.p., intraperitoneal)

ANOVA revealed significant effects of group $[F(4,225)=148.69, p<0.001]$, day $[F(4,225)=950.25, p<0.001]$, and group-day interaction $[F(16,225)=12.27, p<0.001]$.

An i.c.v. injection of $10 \mathrm{nmol} \mathrm{A} \beta_{25-35}$ resulted in a significant decline in spatial learning, with longer latency in searching for the platform. Inter-group analysis showed that $\mathrm{A} \beta$ increased escape latency compared with control group $(p<0.001)$ (Fig. 1).

Intraperitoneal administration of $0.1,0.2$, and $0.3 \mathrm{IU}$ insulin did not improve the learning behavior on training days and no significant differences were found compared with the NS-received AD rats $(p>0.05)$ (Fig. 1).

\section{Effect of intraperitoneal insulin administration on reference memory}

In various groups, the total swimming time in the target quadrant in the probe test was significantly different $[F(4,49)=123.39, p<0.001]$. Post hoc analysis showed a significant effect of $A \beta$ injection on the time spent in the target quadrant compared with the control group $(p<0.001)$. However, none of $0.1,0.2$, and 0.3 IU intraperitoneal insulin had improving effect on reference memory in $\mathrm{AD}$ rats (Fig. 2).

\section{Effect of intranasal insulin administration on working memory}

Groups and days in intranasal administration of insulin were similar to the intraperitoneal administration of insulin. Two-way ANOVA revealed significant effects of group $[F(4,225)=252.67, p<0.001]$, day $[F(4,225)=994.45, p<0.001]$, and group-day interaction $[F(16,225)=13.27, p<0.001]$.

$\mathrm{A} \beta$ administration resulted in a significant decline in spatial learning, with longer latency in searching for the platform. Inter-group analysis showed that $A \beta$ increased escape latency compared with the control group $(p<0.001)$. 

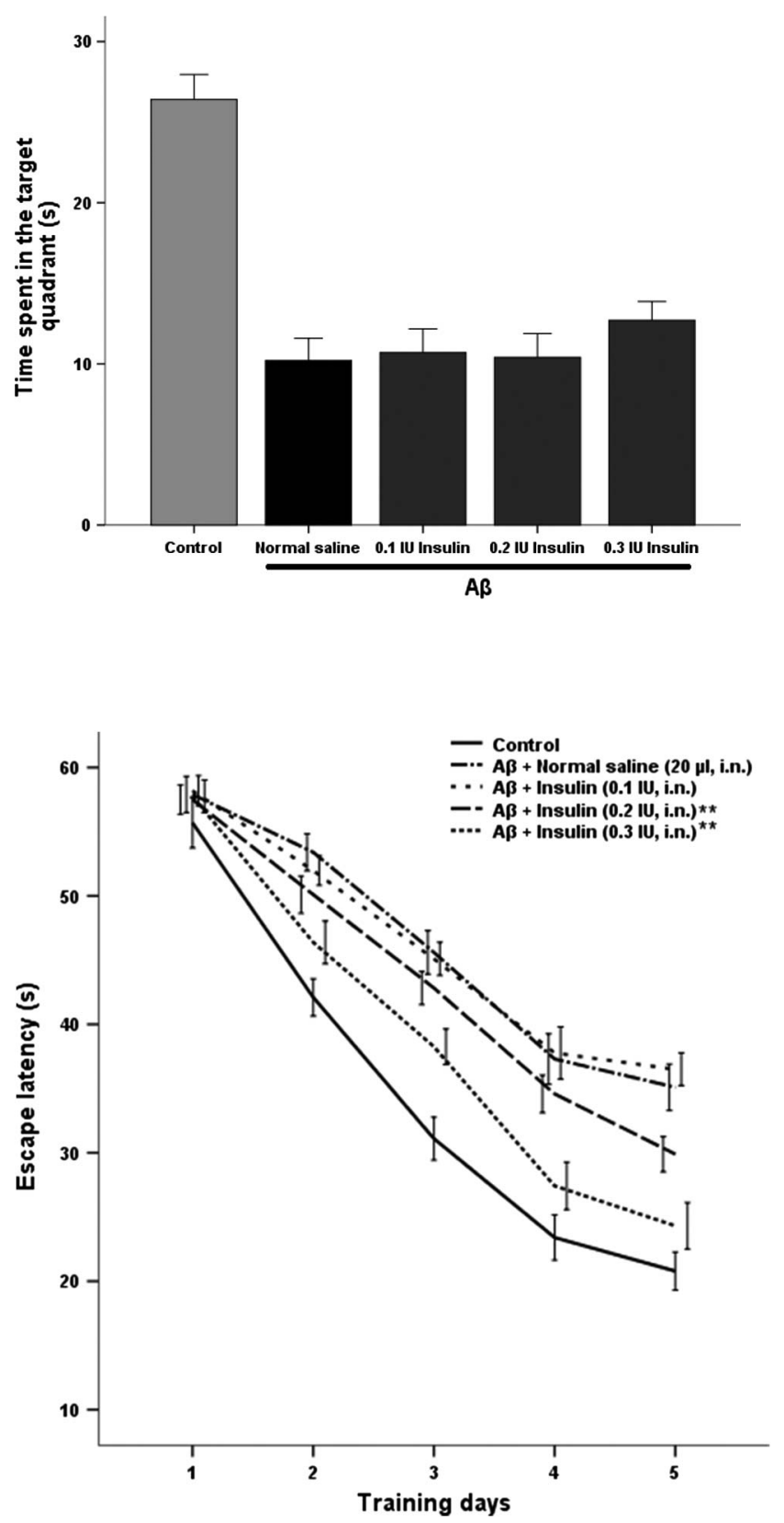

Fig. 2. Average time spent in target quadrant in probe trials in different intraperitoneal groups. Each bar represents the mean \pm SEM
Fig. 3. Average escape latencies during training days on the hidden platform task in different groups. Each dot represents the mean \pm SEM. ${ }^{* *} p<0.001$ compared with the $\mathrm{A} \beta+\mathrm{NS}$ group. (Repeated measure followed by one-way ANOVA and inter-group analysis) (i.n., intranasal)

Intranasal administration of 0.1 IU insulin did not improve the learning behavior and training days, and no significant differences were found compared with the NS-received $A \beta$ group $(p>0.05)$. However, treatment with 0.2 and 0.3 IU intranasal insulin improved the acquisition performance compared with the A $\beta+\mathrm{NS}$ group $(p<0.001)$ (Fig. 3). 


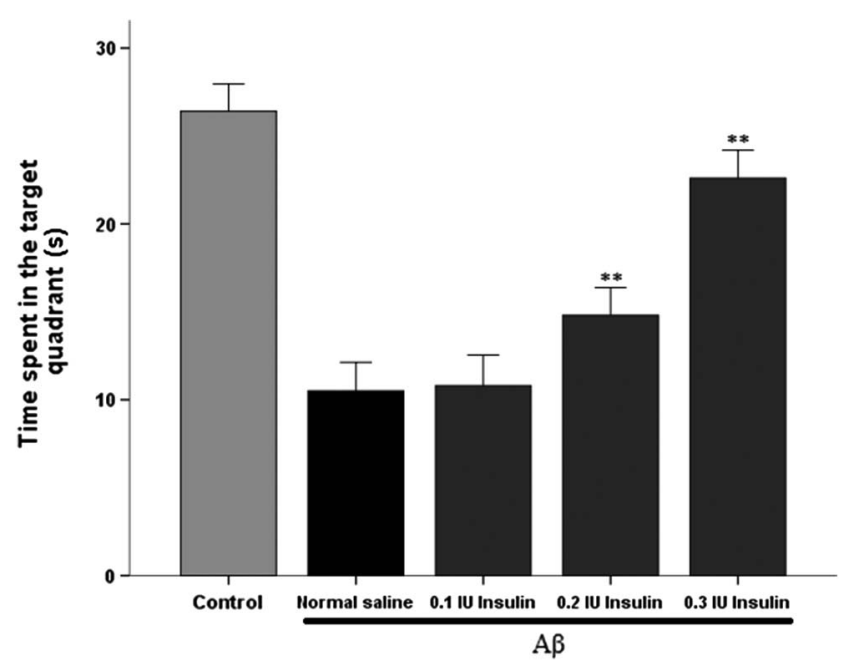

Fig. 4. Average time spent in target quadrant in probe trials in different intranasal groups. Each bar represents the mean $\pm \mathrm{SEM}$.

$* * p<0.001$ compared with the NS-received $\mathrm{A} \beta$ rats. (One-way ANOVA followed by the post hoc Tukey test)

\section{Effect of intranasal insulin administration on reference memory}

In the probe trials, the percentages of total swimming time in the target quadrant were significantly different in various groups $[F(4,49)=100.17, p<0.001]$. Post hoc analysis showed that treatment with 0.2 or $0.3 \mathrm{IU}$ intranasal insulin reversed the reference memory impairments induced by $\mathrm{A} \beta_{25-35}(p<0.001)$ (Fig. 4).

\section{Discussion}

Fast, acute, and non-invasive administration of the treatments is the best method of drug delivery in patients with $\mathrm{AD}$ (28). On the other hand, restriction of the entry of therapeutics into the CNS by BBB is one of the major reasons that causes treatment failure (38). Intranasal delivery of the therapeutics is a useful strategy to treat variety of CNS diseases such as AD by bypassing BBB (8). There is evidence that direct acute administration of insulin into the CNS may improve cognitional performance in AD (35). Hence, this study was designed to evaluate the effect of intranasal administration of insulin on A $\beta$-received rat.

The MWM test is used in the study of the neurobiology and neuropharmacology of spatial learning and memory, and it has an important role in the validation of rodent models for neurocognitive disorders such as $\operatorname{AD}(6,50)$. Therefore, in this study, we used the MWM test for the validation of the effect of insulin therapy on AD rat models.

Intracerebroventricular administration of $A \beta$ in rats is used as a good model for certain aspects of $\mathrm{AD}$, and many studies have used this model for $\mathrm{AD}$ modeling $(34,42)$. In this study, intracerebroventricular administration of $A \beta$ showed a significant impairment in learning and memory, which was in line with other studies $(7,47)$.

Resistance to insulin action within the CNS or diabetes mellitus type III is associated with $\mathrm{AD}$, depression, and other neurologic diseases (4). High concentrations of insulin receptors have been reported in the cerebral cortex and hippocampus (52), so insulin could have direct effects on activity and cognitive function in the CNS (22). It influences cognitive 
functions by modulating neurotransmitter release and synaptic plasticity (24). Also, it modulates acetylcholine and norepinephrine levels in brain and influences cognitive function $(19,26)$.

According to the study by Wang et al. (53), induction of diabetes in transgenic AD mice promotes the processing of $A \beta$ precursor protein and results in increased $A \beta$ generation, neuritic plaque formation, and spatial memory deficits. On the other hand, an accumulating body of evidence shows that $A \beta$ binds to the insulin receptor and disrupts insulin signaling and long-term potentiation induction $(12,15)$. Insulin also modulates glucose utilization in the hippocampus and other brain regions and facilitates memory at optimal levels in normal metabolism (31). In addition, insulin participates in learning and memory by regulating different pathways, such as expression of insulin receptor, insulin receptor substrate, phosphoinositide 3-kinase, and protein kinase B (33).

Peripheral administration of insulin did not improve the learning behavior and memory index in doses that were used in this study. Freude et al. (21) demonstrated that reduced insulin signaling increases tau hyperphosphorylation in CNS. In another study, Chen et al. (9) showed that intranasal insulin prevents anesthesia-induced hyperphosphorylation of tau in 3xTg-AD mice. Also, in the study by Yang et al. (54), subcutaneous insulin delivery did not reduce brain tau phosphorylation.

Radioactively labeled insulin studies confirm that it crosses the BBB by a saturable mechanism. Banks et al. $(2,3)$ demonstrated that insulin crosses the BBB by a saturable transport system. These levels of insulin slightly affect $A \beta$ level, but it does not improve the learning behavior and memory index in rat model.

In this study, 0.1 IU intranasal insulin administration did not improve working and reference memory, but 0.2 and 0.3 IU insulin significantly facilitated process of working and reference memory. According to Zhang et al. (55) in memory-deficient mice, $1.75 \mathrm{IU} /$ day of intranasal insulin for 1 week was shown to prevent anesthesia -induced spatial learning and memory loss.

Babri et al. (1) showed that intra-hippocampal injections of insulin enhance memory. This supports that insulin plays an important role in memory formation.

The study of Amnon revealed that a significant quantity of fluorescently labeled insulin can be effectively delivered to the brain by intranasal administration of formulated microemulsion. The study suggests that intranasal delivery of low-dose insulin would be a potential treatment in pathologic conditions, such as AD (5). The study of Subramanian and John confirmed that intranasal insulin administration significantly reduced $A \beta$ level in rat brain (49). Also, Yang et al. (54) found that insulin treatment could reduce tau hyperphosphorylation in AD rat brains. In addition, evidence shows that enhancing insulin signaling in the brain is a useful therapeutic option to overcome the CNS insulin resistance in $\mathrm{AD}(46)$.

Intranasal insulin delivery occurs through extracellular transport, olfactory, and trigeminal perivascular channels, as well as possibly via axonal transport pathways $(29,51)$. The olfactory nerve has physiologic attributes that provide extracellular and intracellular pathways into the CNS and bypass the BBB (25). Therefore, intranasal administration technique is a unique system of drug delivery to the CNS without significant changes in plasma insulin or glucose levels (27).

It can be concluded that enhancing brain insulin signaling improves memory and learning processes in $\mathrm{AD}$; however, further investigations are needed to clarify the exact mechanisms by which intranasal insulin improves cognitive performance. 


\section{REFERENCES}

1. Babri S, Badie HG, Khamenei S, Seyedlar MO: Intrahippocampal insulin improves memory in a passiveavoidance task in male wistar rats. Brain Cogn. 64, 86-91 (2007)

2. Banks WA, Jaspan JB, Huang W, Kastin AJ: Transport of insulin across the blood-brain barrier: saturability at euglycemic doses of insulin. Peptides 18, 1423-1429 (1997)

3. Banks WA, Kastin AJ: Differential permeability of the blood-brain barrier to two pancreatic peptides: insulin and amylin. Peptides 19, 883-889 (1998)

4. Banks WA, Owen JB, Erickson MA: Insulin in the brain: there and back again. Pharmacol. Ther. 136, 82-93 (2012)

5. Botner S, Friedman A, Amnon C: Direct delivery of intranasal insulin to the brain via microemulsion as a putative treatment of CNS functioning disorders. J. Nanomed. Nanotechnol. 3, 136 (2012)

6. Bromley-Brits K, Deng Y, Song W: Morris water maze test for learning and memory deficits in Alzheimer's disease model mice. J. Vis. Exp. 53, e2920 (2011)

7. Cetin F, Yazihan N, Dincer S, Akbulut G: The effect of intracerebroventricular injection of beta amyloid peptide (1-42) on caspase-3 activity, lipid peroxidation, nitric oxide and NOS expression in young adult and aged rat brain. Turk. Neurosurg. 23, 144-150 (2013)

8. Chapman CD, Frey WH 2nd, Craft S, Danielyan L, Hallschmid M, Schioth HB, Benedict C: Intranasal treatment of central nervous system dysfunction in humans. Pharm. Res. 30, 2475-2484 (2013)

9. Chen Y, Run X, Liang Z, Zhao Y, Dai CL, Iqbal K, Liu F, Gong CX: Intranasal insulin prevents anesthesiainduced hyperphosphorylation of tau in 3xTg-AD mice. Front. Aging Neurosci. 6, 100 (2014)

10. Cholerton B, Baker LD, Craft S: Insulin, cognition, and dementia. Eur. J. Pharmacol. 719, 170-179 (2013)

11. Craft S, Baker LD, Montine TJ, Minoshima S, Watson GS, Claxton A, Arbuckle M, Callaghan M, Tsai E, Plymate SR, Green PS, Leverenz J, Cross D, Gerton B: Intranasal insulin therapy for Alzheimer disease and amnestic mild cognitive impairment: a pilot clinical trial. Arch. Neurol. 69, 29-38 (2012)

12. Craft S, Cholerton B, Baker LD: Insulin and Alzheimer's disease: untangling the web. J. Alzheimers Dis. 33 , S263-S275 (2013)

13. Craft S, Watson GS: Insulin and neurodegenerative disease: shared and specific mechanisms. Lancet Neurol. 3, 169-178 (2004)

14. Davis TM, Brown SG, Jacobs IG, Bulsara M, Bruce DG, Davis WA: Determinants of severe hypoglycemia complicating type 2 diabetes: the Fremantle diabetes study. J. Clin. Endocrinol. Metab. 95, 2240-2247 (2010)

15. De Felice FG, Vieira MN, Bomfim TR, Decker H, Velasco PT, Lambert MP, Viola KL, Zhao W-Q, Ferreira ST, Klein WL: Protection of synapses against Alzheimer's-linked toxins: insulin signaling prevents the pathogenic binding of A $\beta$ oligomers. Proc. Natl. Acad. Sci. U. S. A. 106, 1971-1976 (2009)

16. de la Monte SM: Brain insulin resistance and deficiency as therapeutic targets in Alzheimer's disease. Curr. Alzheimer Res. 9, 35-66 (2012)

17. Dhuria SV, Hanson LR, Frey WH 2nd: Intranasal delivery to the central nervous system: mechanisms and experimental considerations. J. Pharm. Sci. 99, 1654-1673 (2010)

18. Dominguez RO, Pagano MA, Marschoff ER, Gonzalez SE, Repetto MG, Serra JA: Alzheimer disease and cognitive impairment associated with diabetes mellitus type 2: associations and a hypothesis. Neurologia 29, 567-572 (2013)

19. Figlewicz DP, Szot P, Israel PA, Payne C, Dorsa DM: Insulin reduces norepinephrine transporter mRNA in vivo in rat locus coeruleus. Brain Res. 602, 161-164 (1993)

20. Francis GJ, Martinez JA, Liu WQ, Xu K, Ayer A, Fine J, Tuor UI, Glazner G, Hanson LR, Frey WH 2nd, Toth $\mathrm{C}$ : Intranasal insulin prevents cognitive decline, cerebral atrophy and white matter changes in murine type I diabetic encephalopathy. Brain 131, 3311-3334 (2008)

21. Freude S, Plum L, Schnitker J, Leeser U, Udelhoven M, Krone W, Bruning JC, Schubert M: Peripheral hyperinsulinemia promotes tau phosphorylation in vivo. Diabetes 54, 3343-3348 (2005)

22. Havrankova J, Roth J, Brownstein M: Insulin receptors are widely distributed in the central nervous system of the rat. Nature 272, 827-829 (1978)

23. Henderson JN, Allen KV, Deary IJ, Frier BM: Hypoglycaemia in insulin-treated Type 2 diabetes: frequency, symptoms and impaired awareness. Diabet. Med. 20, 1016-1021 (2003)

24. Hirvonen J, Virtanen KA, Nummenmaa L, Hannukainen JC, Honka M-J, Bucci M, Nesterov SV, Parkkola R, Rinne J, Iozzo P: Effects of insulin on brain glucose metabolism in impaired glucose tolerance. Diabetes 60 , 443-447 (2011) 
25. Illum L: Transport of drugs from the nasal cavity to the central nervous system. Eur. J. Pharm. Sci. 11, 1-18 (2000)

26. Klein W, Stine W, Teplow D: Small assemblies of unmodified amyloid $\beta$-protein are the proximate neurotoxin in Alzheimer's disease. Neurobiol. Aging 25, 569-580 (2004)

27. Leinninger GM, Backus C, Uhler MD, Lentz SI, Feldman EL: Phosphatidylinositol 3-kinase and Akt effectors mediate insulin-like growth factor-I neuroprotection in dorsal root ganglia neurons. FASEB J. 18, 1544-1546 (2004)

28. Li Y-H, Feng L, Zhang G-X, Ma C-G: Intranasal delivery of stem cells as therapy for central nervous system disease. Exp. Mol. Pathol. 98, 145-151 (2015)

29. Lochhead JJ, Thorne RG: Intranasal delivery of biologics to the central nervous system. Adv. Drug Deliv. Rev. 64, 614-628 (2012)

30. Machholz E, Mulder G, Ruiz C, Corning BF, Pritchett-Corning KR: Manual restraint and common compound administration routes in mice and rats. J. Vis. Exp. 67, e2771 (2012)

31. McNay EC, Fries TM, Gold PE: Decreases in rat extracellular hippocampal glucose concentration associated with cognitive demand during a spatial task. Proc. Natl. Acad. Sci. U. S. A. 97, 2881-2885 (2000)

32. Misra A, Ganesh S, Shahiwala A, Shah SP: Drug delivery to the central nervous system: a review. J. Pharm. Pharm. Sci. 6, 252-273 (2003)

33. Morris JK, Burns JM: Insulin: an emerging treatment for Alzheimer's disease dementia? Curr. Neurol. Neurosci. Rep. 12, 520-527 (2012)

34. O'shea SD, Smith IM, McCabe OM, Cronin MM, Walsh DM, O'Connor WT: Intracerebroventricular administration of amyloid $\beta$-protein oligomers selectively increases dorsal hippocampal dialysate glutamate levels in the awake rat. Sensors 8, 7428-7437 (2008)

35. Park CR, Seeley RJ, Craft S, Woods SC: Intracerebroventricular insulin enhances memory in a passiveavoidance task. Physiol. Behav. 68, 509-514 (2000)

36. Paxinos G, Watson C (2004): The Rat Brain in Stereotaxic Coordinates - The New Coronal Set. Academic Press, London, UK

37. Pires A, Fortuna A, Alves G, Falcao A: Intranasal drug delivery: how, why and what for? J. Pharm. Pharm. Sci. 12, 288-311 (2009)

38. Reese TS, Karnovsky MJ: Fine structural localization of a blood-brain barrier to exogenous peroxidase. J. Cell Biol. 34, 207-217 (1967)

39. Reger MA, Watson GS, Frey WH 2nd, Baker LD, Cholerton B, Keeling ML, Belongia DA, Fishel MA, Plymate SR, Schellenberg GD, Cherrier MM, Craft S: Effects of intranasal insulin on cognition in memory-impaired older adults: modulation by APOE genotype. Neurobiol. Aging 27, 451-458 (2006)

40. Sadigh-Eteghad S, Askari-Nejad MS, Mahmoudi J, Majdi A: Cargo trafficking in Alzheimer's disease: the possible role of retromer. Neurol. Sci. 37, 17-22 (2016)

41. Sadigh-Eteghad S, Majdi A, Farhoudi M, Talebi M, Mahmoudi J: Different patterns of brain activation in normal aging and Alzheimer's disease from cognitional sight: meta analysis using activation likelihood estimation. J. Neurol. Sci. 343, 159-166 (2014)

42. Sadigh-Eteghad S, Sabermarouf B, Majdi A, Talebi M, Farhoudi M, Mahmoudi J: Amyloid-beta: a crucial factor in Alzheimer's disease. Med. Princ. Pract. 24, 1-10 (2015)

43. Sadigh-Eteghad S, Talebi M, Farhoudi M, Golzari SE, Sabermarouf B, Mahmoudi J: Beta-amyloid exhibits antagonistic effects on alpha 7 nicotinic acetylcholine receptors in orchestrated manner. J. Med. Hypotheses Ideas 8, 49-52 (2014)

44. Sadigh-Eteghad S, Talebi M, Mahmoudi J, Babri S, Shanehbandi D: Selective activation of $\alpha 7$ nicotinic acetylcholine receptor by PHA-543613 improves A $325-35$-mediated cognitive deficits in mice. Neuroscience 298, 81-93 (2015)

45. Salkovic-Petrisic M, Osmanovic-Barilar J, Knezovic A, Hoyer S, Mosetter K, Reutter W: Long-term oral galactose treatment prevents cognitive deficits in male Wistar rats treated intracerebroventricularly with streptozotocin. Neuropharmacology 77, 68-80 (2014)

46. Schioth HB, Craft S, Brooks SJ, Frey WH 2nd, Benedict C: Brain insulin signaling and Alzheimer's disease: current evidence and future directions. Mol. Neurobiol. 46, 4-10 (2012)

47. Shen WX, Chen JH, Lu JH, Peng YP, Qiu YH: TGF- $\beta 1$ protection against A $\beta_{1-42}$-induced neuroinflammation and neurodegeneration in rats. Int. J. Mol. Sci. 15, 22092-22108 (2014)

48. Sogaard R, Sorensen J, Waldorff FB, Eckermann A, Buss DV, Phung KT, Waldemar G: Early psychosocial intervention in Alzheimer's disease: cost utility evaluation alongside the Danish Alzheimer's Intervention Study (DAISY). BMJ Open 4, e004105 (2014) 
49. Subramanian S, John M: Intranasal administration of insulin lowers amyloid-beta levels in rat model of diabetes. Indian J. Exp. Biol. 50, 41-44 (2012)

50. Terry AV Jr (2009): Spatial navigation (water maze) tasks. In: Methods of Behavior Analysis in Neuroscience, 2nd ed., ed Buccafusco JJ, CRC Press/Taylor \& Francis, Boca Raton, FL, pp. 153-166

51. Thorne RG, Pronk GJ, Padmanabhan V, Frey WH II: Delivery of insulin-like growth factor-I to the rat brain and spinal cord along olfactory and trigeminal pathways following intranasal administration. Neuroscience 127, 481-496 (2004)

52. Unger JW, Livingston JN, Moss AM: Insulin receptors in the central nervous system: localization, signalling mechanisms and functional aspects. Prog. Neurobiol. 36, 343-362 (1991)

53. Wang X, Zheng W, Xie JW, Wang T, Wang SL, Teng WP, Wang ZY: Insulin deficiency exacerbates cerebral amyloidosis and behavioral deficits in an Alzheimer transgenic mouse model. Mol. Neurodegener. 5, 46 (2010)

54. Yang Y, Ma D, Wang Y, Jiang T, Hu S, Zhang M, Yu X, Gong C-X: Intranasal insulin ameliorates tau hyperphosphorylation in a rat model of type 2 diabetes. J. Alzheimers Dis. 33, 329-338 (2013)

55. Zhang Y, Dai CL, Chen Y, Iqbal K, Liu F, Gong CX: Intranasal insulin prevents anesthesia-induced spatial learning and memory deficit in mice. Sci. Rep. 6, 21186 (2016) 